\title{
Optimization of Milk-Based Medium for Efficient Cultivation of Bifidobacterium pseudocatenulatum G4 Using Face-Centered Central Composite-Response Surface Methodology
}

\author{
Khalilah Abdul Khalil, ${ }^{1}$ Shuhaimi Mustafa, ${ }^{2,3}$ Rosfarizan Mohammad, ${ }^{3,4}$ \\ Arbakariya Bin Ariff, ${ }^{3}$ Yamin Shaari, ${ }^{3}$ Yazid Abdul Manap, ${ }^{5}$ Siti Aqlima Ahmad, ${ }^{3}$ \\ and Farrah Aini Dahalan' \\ ${ }^{1}$ Department of Biomolecular Sciences, Faculty of Applied Sciences, Universiti Teknologi MARA, Sec. 2, 40150 Shah Alam, \\ Selangor, Malaysia \\ ${ }^{2}$ Halal Products Research Institute, Universiti Putra Malaysia, Putra Infoport, 43400 Serdang, Selangor, 40150 Shah Alam, \\ Selangor, Malaysia \\ ${ }^{3}$ Faculty of Biotechnology and Biomolecular Sciences, Universiti Putra Malaysia, 4340013 Serdang, Selangor, Malaysia \\ ${ }^{4}$ Institute of Tropical Forestry and Forest Products, Universiti Putra Malaysia, 4340015 Serdang, Selangor, Malaysia \\ ${ }^{5}$ Faculty of Food Science and Technology, Universiti Putra Malaysia, 43400 Serdang, Selangor, Malaysia \\ ${ }^{6}$ The School of Environmental Engineering, Universiti Malaysia Perlis, Kompleks Pengajian Jejawi 3, 02600 Arau, Perlis, Malaysia
}

Correspondence should be addressed to Khalilah Abdul Khalil; khali552@yahoo.com

Received 25 July 2013; Accepted 13 November 2013; Published 12 January 2014

Academic Editor: Filippo Canducci

Copyright (C) 2014 Khalilah Abdul Khalil et al. This is an open access article distributed under the Creative Commons Attribution License, which permits unrestricted use, distribution, and reproduction in any medium, provided the original work is properly cited.

\begin{abstract}
This study was undertaken to optimize skim milk and yeast extract concentration as a cultivation medium for optimal Bifidobacteria pseudocatenulatum G4 (G4) biomass and $\beta$-galactosidase production as well as lactose and free amino nitrogen (FAN) balance after cultivation period. Optimization process in this study involved four steps: screening for significant factors using $2^{3}$ full factorial design, steepest ascent, optimization using FCCD-RSM, and verification. From screening steps, skim milk and yeast extract showed significant influence on the biomass production and, based on the steepest ascent step, middle points of skim milk (6\% wt/vol) and yeast extract $(1.89 \% \mathrm{wt} / \mathrm{vol})$ were obtained. A polynomial regression model in FCCD-RSM revealed that both factors were found significant and the strongest influence was given by skim milk concentration. Optimum concentrations of skim milk and yeast extract for maximum biomass G4 and $\beta$-galactosidase production meanwhile low in lactose and FAN balance after cultivation period were $5.89 \%(\mathrm{wt} / \mathrm{vol})$ and $2.31 \%(\mathrm{wt} / \mathrm{vol})$, respectively. The validation experiments showed that the predicted and experimental values are not significantly different, indicating that the FCCD-RSM model developed is sufficient to describe the cultivation process of G4 using skim-milk-based medium with the addition of yeast extract.
\end{abstract}

\section{Introduction}

Probiotic can be defined as "living microorganisms which when administered in adequate amounts confer a health benefit on the host" [1]. The beneficial effects of probiotic include regulation in immune system, anticarcinogenic, preventing the infection by exogenous microorganisms, vitamin synthesis, and enhancing digestion and absorption of nutrients [2].
Bifidobacteria, the major species of intestinal flora in healthy human, have been widely used in probiotics formulation [3]. Bifidobacteria are anaerobic rods, Gram-positive, and nonspore forming bacteria [4]. Bifidobacterium pseudocatenulatum G4, isolated from breast-fed infants feces, has been identified and characterized as a potential probiotic with many beneficial health effects [5-7]. The antimicrobial properties, adherence ability, antagonistic activity, and ability 
to survive in gut environment for Bifidobacterium pseudocatenulatum G4 have also been reported [8].

Proliferation of bifidobacteria requires appropriate medium which supplies nurturing substances for growth. The use of commercial media to support bacterial growth is limited by its cost [9] and off-flavor generated in food products [10]. Milk is a highly nutritious growth medium for many microorganisms as it is rich in carbohydrates, fat, casein, protein, vitamins, and minerals [11]. However, some microorganisms are unable to grow well in this medium when specific enzymes required for lactose metabolization process are lacking [12]. $\beta$-Galactosidase is an enzyme required to break lactose to galactose and glucose. Most of the bifidobacteria preferred these carbon sources to promote their growth. The production of $\beta$-galactosidase can be enhanced using yeast extract as a nitrogen source [13]. Various concentrations of yeast extract (ranging from $0.3 \%$ to $1.0 \% \mathrm{wt} / \mathrm{vol}$ ) were added into milk (ranging from $10 \%$ to $12 \% \mathrm{wt} / \mathrm{vol}$ ) to enhance growth of probiotics $[14,15]$. Various concentrations of glucose (ranging from $0.5 \%$ to $2.0 \% \mathrm{wt} / \mathrm{vol}$ ) have also been used as a carbon source in the cultivation of probiotic like bifidobacteria [16].

In optimization of milk-based-medium for bifidobacteria growth, it is important to consider $\beta$-galactosidase production by the cells in order to facilitate lactose breakdown into more readily available sugar. In addition, the concomitant use of nitrogen sources is also important to avoid nutrients wastage. Most of the previous studies on the medium optimization for bifidobacteria focused mainly on the maximum biomass production $[8,17]$. To the best of our knowledge, justification involving other responses of growth activities of bifidobacteria in milk medium in order to ensure that the medium has been used competently is not available in the literature.

The optimization of medium concentration or components by conventional approach involves large numbers of experiments which are time consuming and expensive and lack in representing the effects of individual factors. Thus, a statistical approach known as response surface methodology (RSM) has been applied as a tool for process improvement. The main advantage of RSM is the reduced number of experiments or trials required to evaluate multiple parameters and their interactions $[18,19]$. The most commonly design approached is the central composite design. The design allows estimation of all the regression parameters required to fit a second-order model of given responses. Rotability character is the most preferred in any central composite design. This is because this characteristic provides constant variance of the estimated response corresponding to all new observation points that are at the same distance from the center point of the design (in terms of the coded variable).

Therefore, the main objective of this study was to optimize milk-based medium for the improvement of B. pseudocatenulatum G4 cultivation. In this optimization process, there were four responses; namely, (i) cells production, (ii) accumulation of lactose degrading enzyme ( $\beta$-galactosidase), and (iii) residual concentration of lactose and free amino nitrogen remaining in the culture at the end of cultivation, were considered.

\section{Materials and Methods}

2.1. Bacterium and Inoculum Preparation. Probiotic bacterium, B. pseudocatenulatum G4 (G4), was used throughout this study and this bacterium was obtained from the Probiotic Laboratory, Faculty of Food Science and Technology, Universiti Putra Malaysia. G4 was previously isolated from breast-fed infant feces $[5,6]$ and was stored at $-20^{\circ} \mathrm{C}$ in a mixture of glycerol and Trypticase Phytone Yeast (TPY) extract broth (Scharlau-Chemie, Barcelona, Spain), at a ratio of $80: 20$. TPY medium (Scharlau-Chemie, Barcelona, Spain) was used to maintain and to propagate the bacterium [4]. A single colony of the bacterium was transferred from TPY agar to TPY broth and incubated anaerobically at $37^{\circ} \mathrm{C}$ for $24 \mathrm{~h}$. After two successive transfers in TPY broth at $37^{\circ} \mathrm{C}$ for $24 \mathrm{~h}$ under anaerobic condition using Anaerocult A gas packs (Merck, Darmstadt, Germany), the activated culture was then properly diluted and served as the standard inoculum for all cultivations.

2.2. Medium Preparation. Cultivation was carried out in $250 \mathrm{~mL}$ SCHOTT DURAN bottle (Schott Duran, Mainz, Germany). The medium components consist of skim milk (NZMP medium heat skim milk powder, Auckland, New Zealand), yeast extract (Bio Springer, Maisons-Alfort Cedex, France), and glucose (Merck, Darmstadt, Germany). All components were prepared in separate bottle and sterilized at $121^{\circ} \mathrm{C}$ for $15 \mathrm{~min}$. Once cooled at room temperature, the components were mixed prior to inoculation with $10^{4} \mathrm{cfu} / \mathrm{mL}$ of G4. The bottle was then incubated at $37^{\circ} \mathrm{C}$ for $21 \mathrm{~h}$ in an anaerobic condition. The culture $\mathrm{pH}$ was not controlled in all experiments. During the cultivation, $10 \mathrm{~mL}$ of samples was taken at $3 \mathrm{~h}$ intervals for analysis.

2.3. Lactose Determination. The amount of lactose in the samples was determined using HPLC method as described by Hou et al. with some modifications [20]. One $\mathrm{mL}$ of sample was centrifuged at $13000 \mathrm{rpm}$ for $10 \mathrm{~min}$. The clear fraction was filtered through a $0.2 \mu \mathrm{m}$ nylon membrane filter and injected onto HPLC system (Alliance 2690/5: Waters Corporation, Milford, CA), equipped with a $4.6 \mathrm{~mm}$ $\times 150 \mathrm{~mm}$ Agilent Zorbax Carbohydrate Analysis column (Agilent Technologies Inc., USA). The mobile phase used is $75 \%(\mathrm{v} / \mathrm{v})$ acetonitrile (Fisher, HPLC grade). The flow rate was set at $1.4 \mathrm{~mL} \mathrm{~min}^{-1}$ and the analysis was carried out at $30^{\circ} \mathrm{C}$ using a refractive index detector (RI-1371, Waters Corporation, Milford, CA).

2.4. Free Amino Nitrogen Analyses. Free amino nitrogen (FAN) presence in the sample was determined using ninhydrin analysis described by Hwang and Ederer with some modifications [21]. A sample $(1 \mathrm{~mL})$ was centrifuged at $13000 \mathrm{rpm}$ for $10 \mathrm{~min}$. The clear fraction was collected and diluted into $50 \mathrm{~mL}$ distilled water and $2 \mathrm{~mL}$ of the diluted sample was then transferred into test tubes. Ninhydrin solution $(0.35 \mathrm{~g}$ ninhydrin into $100 \mathrm{~mL}$ of a $1: 1$ mixture of acetone and butanol) was then added and the tubes were covered with a piece of parafilm to avoid the loss of solvent 
due to evaporation. The tubes were then heated in a boiling water bath $\left(80^{\circ} \mathrm{C}-100^{\circ} \mathrm{C}\right)$ for $15 \mathrm{~min}$ before being transferred to a cold water bath. The dilution reagent $(5 \mathrm{~mL})$ was then added and mixed and the absorbance was read at $570 \mathrm{~nm}$ using spectrophotometer (UV-Vis 1601 spectrophotometer, Shimadzu, Japan). Distilled water was used as a blank and glycine (Merck, Darmstadt, Germany) was used as a standard.

2.5. $\beta$-Galactosidase Analyses. $\beta$-Galactosidase was assayed on nonpermeabilized and permeabilized cells. The culture was centrifuged at $11000 \mathrm{rpm}$ for $10 \mathrm{~min}$ at $4^{\circ} \mathrm{C}$. Subsequently, the resulting supernatant was discarded by aspiration. The cell pellet was washed twice with $\mathrm{Z}$ buffer $(0.1 \mathrm{M}$ phosphate$\mathrm{pH} 7 ; 10 \mathrm{mM} \mathrm{MgSO}_{4} \cdot 7 \mathrm{H}_{2} \mathrm{O} ; 1 \mathrm{mM} \mathrm{CaCl} 2$ ) and concentrated by 10 -fold. Permeabilization was accomplished by the addition of $0.5 \mathrm{~mL}$ of Triton X-100 (5\% vol/vol in Z buffer) into $0.5 \mathrm{~mL}$ cell suspension with mixing using vortex mixer. The mixture was incubated at $37^{\circ} \mathrm{C}$ for $10 \mathrm{~min}$ and then centrifuged at $14000 \mathrm{rpm}$ for $15 \mathrm{~min}$ and the resulting supernatant served as the enzyme source. The activity of $\beta$-galactosidase was then assayed essentially according to the method described by Nagy et al. (2001) [22]. The reaction mixture was composed of $0.5 \mathrm{~mL}$ of enzyme sample and $0.5 \mathrm{~mL}$ of $15 \mathrm{mM}$ o-nitrophenyl $\beta$-d-galactopyranoside (Sigma Chemical Co., St. Louis, MO) in $0.03 \mathrm{M}$ sodium phosphate buffer ( $\mathrm{pH}$ 6.8). Once a faint yellow tint appeared, the reaction was terminated by adding $0.1 \mathrm{M}$ sodium carbonate. The absorbance was measured using a spectrophotometer at $420 \mathrm{~nm}$ wavelength (UV-Vis 1601 spectrophotometer, Shimadzu, Japan). One unit of $\beta$-galactosidase activity was defined as the amount of enzyme catalyzing the formation of $1 \mu \mathrm{mol}$ of o-nitrophenyl per min under the assay condition.

2.6. Microbiological Analyses. For viable cells enumeration, samples were serially diluted using $0.1 \%$ (wt/vol) sterile peptone water (Merck, Darmstadt, Germany) and plated in duplicate onto TPY agar. The plates were incubated in anaerobic jars containing Anaerocult A (Merck, Darmstadt, Germany) at $37^{\circ} \mathrm{C}$ for $48 \mathrm{~h}$. All plates with 30 to 300 colonies were counted and the viability was expressed as $\log _{10} \mathrm{cfu} / \mathrm{mL}$.

2.7. Experimental Design and Statistical Analyses. DesignExpert software (Stat-Ease Inc., Minneapolis, MN, USA, version 6.0.6) was used to design the experiment in this study. First, initial screening experiments were performed to evaluate the significant effects of skim milk, yeast extract, and glucose on biomass production using a $2^{3}$ full factorial design. Each factor was coded at three levels between -1 and +1 , with 5 times replication of center point (0), where the variables of factors were changed in the ranges. The factorial design resulting in 26 experimental runs (including duplicates and 5 middle points run). In the second step, a first-order empirical equation was applied to exclude insignificant factors and to generate the steepest ascent path to facilitate the maximum increase in response. The steepest ascent design was based on results of the equation from the screening step of which only factors with significant effects on response were used and fixed at their zero coded value. The insignificant factors were eliminated from the design. The path begins at the centre point of design and stretches out linearly in order to determine the suitable ranges within significant factors which tend to approach the optimal condition. The third step involved further optimization of significant factors using face-centered central composite design (FCCD). FCCD is an effective design that is used for sequential experimentation and provides reasonable amount of information for testing the goodness of fit and does not require large number of design points thereby reducing the overall cost associated with the experiment [23]. In this design, four responses, namely, biomass $\left(y_{1}, \log _{10} \mathrm{cfu} / \mathrm{mL}\right)$ and $\beta$-galactosidase production, $\left(y_{2}, \mathrm{U} / \mathrm{mL}\right)$ as well as residual lactose $\left(y_{3}, \mathrm{~g} / \mathrm{L}\right)$ and FAN $\left(y_{4}, \mathrm{mg} / \mathrm{L}\right)$ remaining in the culture were determined. There were three coded factor levels, $-1,0$, and +1 (where -1 corresponded to the low level of each factor, 0 to the middle level, and +1 to the high level). The coded values were determined using

coded value

$$
=\frac{\text { actual level }-(\text { maximum level }- \text { minimum level })}{(1 / 2)(\text { maximum value }- \text { minimum })} .
$$

The center point was repeated five times in order to evaluate the curvature and the experiment replication facilitated the pure error estimation, so that the significant lack of fit of the models could be predicted. All the 26 experiments were carried out in duplicate for $21 \mathrm{~h}$.

\section{Results and Discussion}

3.1. Initial Screening of Significant Medium Components and the Steepest Ascent. The effect of skim milk $\left(x_{1}\right)$, yeast extract $\left(x_{2}\right)$, and glucose $\left(x_{3}\right)$ on biomass production $\left(y_{1}\right)$ during the cultivation of G4 using $2^{3}$ full factorial design is shown in Table 1. The maximum biomass (ranging from 4.495 to $7.638 \log _{10} \mathrm{cfu} / \mathrm{mL}$ ) was obtained at $21 \mathrm{~h}$ of cultivation. The analysis of variance (ANOVA) of the first-order model is shown in Table 2 while the regression analysis of the model is shown in Table 3. The model was significant and only $1.12 \%$ of the total variation was observed due to noise. The model was linear with insignificant $(P>0.05)$ curvature. The regression analysis of the variables showed that skim milk ( $P=0.007)$ was the only significant factor while yeast extract and glucose were insignificant with $P$ values higher than 0.05 (Table 3 ). Since yeast extract $\left(x_{2}\right)$ was the sole nitrogen, it must be considered in the medium optimization. Improvement of growth of bifidobacteria could be achieved using yeast extract at concentration higher than $1.0 \%$ without the addition of glucose [17]. As a result, final-order equation (coded term) was generated based on the first-order model to determine the biomass production response $\left(y_{1}\right)$ to the medium composition containing skim milk $\left(x_{1}\right)$ and yeast extract $\left(x_{2}\right)$ factors, which give

$$
y_{1}=6.2+1.09 x_{1}+0.3 x_{2} .
$$


TABLE 1: The $2^{3}$ full factorial design and responses for screening experiments.

\begin{tabular}{lcccc}
\hline Run & Skim milk (\%wt/vol) & Yeast extract $(\%$ wt/vol) & Glucose (\% wt/vol) & $\begin{array}{c}\text { Response } \\
\text { Maximum biomass } \\
\text { (log } 10 \\
\text { CFU per milliliter) }\end{array}$ \\
\hline 1 & $2(-1)$ & $0.5(-1)$ & $0.5(-1)$ & 4.495 \\
2 & $2(-1)$ & $0.5(-1)$ & $1.5(+1)$ & 4.789 \\
3 & $2(-1)$ & $3(+1)$ & $0.5(-1)$ & 5.335 \\
4 & $2(-1)$ & $3(+1)$ & $1.5(+1)$ & 5.800 \\
5 & $4(0)$ & $1.75(0)$ & $1(0)$ & 6.417 \\
6 & $4(0)$ & $1.75(0)$ & $1(0)$ & 6.671 \\
7 & $4(0)$ & $1.75(0)$ & $1(0)$ & 6.075 \\
8 & $4(0)$ & $1.75(0)$ & $1(0)$ & 6.824 \\
9 & $4(0)$ & $1.75(0)$ & $1(0)$ & 6.874 \\
10 & $6(+1)$ & $0.5(-1)$ & $0.5(-1)$ & 7.158 \\
11 & $6(+1)$ & $0.5(-1)$ & $1.5(+1)$ & 7.173 \\
13 & $6(+1)$ & $3(+1)$ & $0.5(-1)$ & 7.204 \\
\end{tabular}

TABLE 2: ANOVA results of the first-order model for $2^{3}$ full factorial design.

\begin{tabular}{|c|c|c|c|c|c|}
\hline Source of variation or factors & $\mathrm{DF}^{\mathrm{a}}$ & Sum of squares & Mean square & $F$ or $t$ value & $P$ value \\
\hline Model $^{\mathrm{b}}$ & 7 & 10.75 & 1.54 & 14.09 & 0.0112 \\
\hline Curvature & 7 & 0.43 & 0.43 & 0.071 & 0.1182 \\
\hline Pure error & 4 & 0.44 & 0.11 & 3.94 & \\
\hline Correlation total & 12 & 11.61 & & & \\
\hline
\end{tabular}

${ }^{\mathrm{a} D F}$ : degree of freedom.

${ }^{\mathrm{b}} R^{2}: 96.10 \%$.

Significant at $\alpha=0.05$.

TABLE 3: Regression analysis of the $2^{3}$ full factorial design with maximum biomass $\left(\log _{10} \mathrm{cfu} / \mathrm{mL}\right)$ as the response.

\begin{tabular}{lcc}
\hline Variable & $F$ Value & $P$ value \\
\hline$x_{1}{ }^{\mathrm{a}}$ & 87.94 & 0.0007 \\
$x_{2}$ & 6.40 & 0.0647 \\
$x_{3}$ & 1.67 & 0.2658 \\
$x_{1} x_{2}$ & 2.06 & 0.2246 \\
$x_{1} x_{3}$ & 0.11 & 0.7572 \\
$x_{2} x_{3}$ & 0.40 & 0.5623 \\
$x_{1} x_{2} x_{3}$ & 0.07 & 0.8034 \\
Model & 14.09 & 0.0112 \\
Curvature & 3.94 & 0.1182 \\
CV $=2.78 \%$ & $R^{2}=0.96$ & Adjusted $R^{2}=0.90$
\end{tabular}

${ }^{\mathrm{a}} x_{1}$ represents skim milk concentration in \% (wt/vol).

$x_{2}$ represents yeast extract concentration \% (wt/vol).

$x_{3}$ represents glucose concentration $\%(\mathrm{wt} / \mathrm{vol})$.

For every unit increase in $x_{1}$, an increase of 1.09 units in $y_{1}$ is predicted (2). On the other hand, for every unit increase in $x_{2}, 0.30$ units of increase in $y_{1}$ is expected. Between these two factors, skim milk $\left(x_{1}\right)$ gave more effect than yeast extract $\left(x_{2}\right)$ on biomass production $\left(y_{1}\right)$. This equation was further used as the fundamental scale in the subsequent step which was the steepest ascent. The path of the steepest ascent was determined based on the increase in $0.10 \%$ (wt/vol) of $x_{1}$ and the movement was generated along the path until no improvement occurred. Five design units were developed based on $0.10 / 0.10=1$. Hence, the movement of $x_{2}$ was 0.28 design units $(0.3 / 1.09=0.28)$. As for natural factor, $x_{1}$ movement was based on coded factor $\times$ lower point of $x_{1}$ $(1 \times 2=2)$. Thus, movement of $x_{2}$ natural factor involved $0.28 \times 0.5=0.14$. The path coordination of the steepest ascent was generated and is shown in Table 4 . The highest biomass production can be observed in the third step of the steepest ascent coordinates with the value of $7.68 \pm$ $0.17 \log _{10} \mathrm{cfu} / \mathrm{mL}$ from the combination of skim milk $(6 \%$ (wt/vol)) and yeast extract $(1.89 \%$ (wt/vol)). After the third step of coordinates, declining in biomass production was observed. Consequently, this combination was selected as the middle point for further optimization.

3.2. Optimization of Medium Component. The experimental responses for the optimization of skim milk and yeast extract are shown in Table 5. Skim milk concentration $\left(x_{1}\right)$ was in the range of $4 \%(\mathrm{wt} / \mathrm{vol})$ to $8 \%(\mathrm{wt} / \mathrm{vol})$ with $6 \%(\mathrm{wt} / \mathrm{vol})$ as a center point whereas, for yeast extract $\left(x_{2}\right)$, the range of $1 \%$ (wt/vol) to $2.8 \%(\mathrm{wt} / \mathrm{vol}$ ) with $1.9 \%(\mathrm{wt} / \mathrm{vol}$ ) as a center point was fixed further optimization. Center points with a coded 
TABLE 4: The steepest ascent coordination path for all chosen factors at coded and natural levels.

\begin{tabular}{|c|c|c|c|c|c|}
\hline \multirow{2}{*}{ Step } & \multicolumn{2}{|c|}{ Coded factor $^{a}$} & \multicolumn{2}{|c|}{ Natural factor ${ }^{\mathrm{b}}(\% \mathrm{wt} / \mathrm{vol})$} & \multirow{2}{*}{ Maximum biomass $\left(\log _{10} \mathrm{cfu} / \mathrm{mL}\right)^{\mathrm{e}}$} \\
\hline & $\varepsilon_{1}$ & $\varepsilon_{2}$ & $x_{1}$ & $x_{2}$ & \\
\hline Base $^{c}$ & 0 & 0 & 4 & 1.75 & $5.77 \pm 0.24$ \\
\hline$\Delta^{\mathrm{d}}$ & 1 & 0.28 & 2 & 0.14 & $4.05 \pm 0.09$ \\
\hline Base $+\Delta$ & 1 & 0.28 & 6 & 1.89 & $7.68 \pm 0.17$ \\
\hline Base $+2 \Delta$ & 2 & 0.56 & 8 & 2.03 & $7.66 \pm 0.68$ \\
\hline Base $+3 \Delta$ & 3 & 0.84 & 10 & 2.17 & $7.65 \pm 0.26$ \\
\hline Base $+4 \Delta$ & 4 & 1.12 & 12 & 2.31 & $7.63 \pm 0.66$ \\
\hline Base $+5 \Delta$ & 5 & 1.40 & 14 & 2.45 & $7.61 \pm 0.04$ \\
\hline
\end{tabular}

${ }^{\mathrm{a}}$ Coded factor $\varepsilon_{1}$ : skim milk, $\varepsilon_{2}$ : yeast extract.

${ }^{\mathrm{b}}$ Natural factor $x_{1}$ : skim milk, $x_{2}$ : yeast extract.

${ }^{\mathrm{c}}$ Based: 0 for coded factor and middle point for natural factor.

${ }^{\mathrm{d}}$ Movement units (coded factor $\left.\varepsilon_{1}: 0.1 / 0.1, \varepsilon_{2}: 0.3 / 1.09\right)$ (natural factor: coded factor $x$ lower point).

${ }^{\mathrm{e}}$ Maximum biomass of $B$. pseudocatenulatum $\mathrm{G} 4\left(\log _{10} \mathrm{cfu} / \mathrm{mL}\right)$ at $21 \mathrm{~h}$ of cultivation period. Values are mean of triplicates.

TABLE 5: Experimental design and results using face-centered full factorial design (FCCD).

\begin{tabular}{|c|c|c|c|c|c|c|c|c|}
\hline \multirow[b]{2}{*}{ Run } & \multicolumn{2}{|c|}{ Skim milk, $x_{1}$} & \multicolumn{2}{|c|}{ Yeast extract, $x_{2}$} & \multicolumn{4}{|c|}{ Responses $^{\mathrm{a}}$} \\
\hline & $\begin{array}{l}\text { Coded } \\
\text { value }\end{array}$ & $\begin{array}{l}\text { Actual } \\
\text { value }\end{array}$ & $\begin{array}{l}\text { Coded } \\
\text { value }\end{array}$ & $\begin{array}{l}\text { Actual } \\
\text { value }\end{array}$ & $\begin{array}{c}\text { Max. biomass, } \\
y_{1} \\
\left(\log _{10} \mathrm{cfu} / \mathrm{mL}\right)\end{array}$ & $\begin{array}{c}\beta \text {-Galactosidase } \\
\text { production } y_{2} \\
(\mathrm{U} / \mathrm{mL})\end{array}$ & $\begin{array}{c}\text { Lactose balance } \\
y_{3}(\mathrm{~g} / \mathrm{L})\end{array}$ & $\begin{array}{c}\text { FAN balance } y \\
(\mathrm{mg} / \mathrm{L})\end{array}$ \\
\hline 1 & -1 & 4.0 & -1 & 1.0 & 5.15 & 0.19 & 4.59 & 198.24 \\
\hline 2 & -1 & 4.0 & 0 & 1.9 & 5.18 & 3.03 & 4.51 & 209.58 \\
\hline 3 & -1 & 4.0 & +1 & 2.8 & 5.22 & 3.13 & 4.40 & 213.24 \\
\hline 4 & 0 & 6.0 & -1 & 1.0 & 7.09 & 7.06 & 10.83 & 229.15 \\
\hline 5 & 0 & 6.0 & 0 & 1.9 & 7.15 & 8.37 & 11.53 & 237.06 \\
\hline 6 & 0 & 6.0 & 0 & 1.9 & 7.11 & 9.40 & 11.58 & 231.04 \\
\hline 7 & 0 & 6.0 & 0 & 1.9 & 7.12 & 9.32 & 11.81 & 234.65 \\
\hline 8 & 0 & 6.0 & 0 & 1.9 & 7.14 & 8.35 & 11.91 & 238.98 \\
\hline 9 & 0 & 6.0 & 0 & 1.9 & 7.16 & 9.38 & 11.84 & 233.14 \\
\hline 10 & 0 & 6.0 & +1 & 2.8 & 7.13 & 8.41 & 12.90 & 359.76 \\
\hline 11 & +1 & 8.0 & -1 & 1.0 & 7.26 & 7.02 & 22.41 & 287.53 \\
\hline 12 & +1 & 8.0 & 0 & 1.9 & 7.23 & 6.27 & 19.10 & 290.59 \\
\hline 13 & +1 & 8.0 & +1 & 2.8 & 7.11 & 6.18 & 25.25 & 318.70 \\
\hline
\end{tabular}

${ }^{a}$ All factorial and axial points are means of duplicate.

$(0,0)$ were repeated five times. The importance of medium components for cultivation process can be considered by their effect on biomass production $\left(y_{1}\right)$ and $\beta$-galactosidase production $\left(y_{2}\right)$ as well as the residual lactose $\left(y_{3}\right)$ and free amino nitrogen $\left(y_{4}\right)$ remaining in the culture. The responses $\left(y_{1}, y_{2}, y_{3}\right.$, and $\left.y_{4}\right)$ were fitted with quadratic polynomial model and subsequently produced the response surface as expressed in (3). Consider

$$
y=\beta_{0}+\beta_{1} x_{1}+\beta_{2} x_{2}+\beta_{11} x_{1}^{2}+\beta_{11} x_{2}^{2}+\varepsilon_{i}
$$

where $x_{1}$ and $x_{2}$ represent coded independent factors of skim milk and yeast extract, respectively. Meanwhile, $\beta_{0}, \beta_{1}, \beta_{2}$, $\beta_{11}$, and $\beta_{22}$ are coefficients and $\varepsilon_{i}$ is the random error.
3.2.1. Optimization of Biomass Production ( $\left.y_{1}\right)$. By applying regression analysis on the experimental data, biomass production can be described by the second-order equation

$$
\begin{aligned}
y_{1}= & 7.14+1.01 x_{1}-6.67 \times 10^{-3} x_{2}-0.93 x_{1}^{2} \\
& -0.023 x_{2}^{2}-0.055 x_{1} x_{2} .
\end{aligned}
$$

Skim milk $\left(x_{1}, x_{1}^{2}\right)$ was shown to be highly significant $(P<$ $0.001)$ whereas yeast extract $\left(x_{2}, x_{2}^{2}\right)$ presented less influence towards biomass production. As a result, the quadratic model was further reduced with insignificant model term excluded. However, the addition of yeast extract $\left(x_{2}\right)$, as nitrogen source, in the milk medium must be considered to enhance 
TABLE 6: ANOVA and regression analysis for the response of biomass production $\left(y_{1}\right)$ : optimization of skim milk (\% wt/vol) and yeast extract (\% wt/vol).

\begin{tabular}{|c|c|c|c|c|c|}
\hline Source of variation & Sum of squire or coefficient estimate & $\mathrm{DF}^{\mathrm{a}}$ & MS or Std error & $F$ value & $P$ value \\
\hline Model $^{\mathrm{b}}$ & 8.95 & 4 & 2.24 & 2893.35 & $<0.001$ \\
\hline Residual & $6.186 E-003$ & 8 & $7.732 E-004$ & & \\
\hline Lack of fit & $4.466 E-003$ & 4 & $1.116 E-003$ & 2.60 & 0.1890 \\
\hline Pure error & $1.720 E-003$ & 4 & $4.300 E-004$ & & \\
\hline Total & 8.95 & 12 & & & \\
\hline \multicolumn{6}{|l|}{ Factor $^{c}$} \\
\hline Intercept & 7.14 & 1 & & & \\
\hline$x_{1}$ & 1.01 & 1 & 0.011 & 7889.68 & $<0.001^{\mathrm{d}}$ \\
\hline$x_{2}$ & $-6.667 E-003$ & 1 & 0.011 & 0.34 & 0.5732 \\
\hline$x_{1}^{2}$ & -0.94 & 1 & 0.015 & 3667.73 & $<0.001^{\mathrm{d}}$ \\
\hline$x_{1} x_{2}$ & -0.055 & 1 & 0.014 & 15.65 & $0.0042^{\mathrm{d}}$ \\
\hline
\end{tabular}

${ }^{\mathrm{a} D F}$ : degree of freedom.

${ }^{\mathrm{b}} R^{2}=99.93 \%$.

${ }^{\mathrm{c}} x_{1}$, skim milk (\% wt/vol), $x_{2}$, yeast extract (\% wt/vol).

${ }^{\mathrm{d}}$ Significant at $\alpha=0.05$.

TABLE 7: Comparison experiments using optimized skim milk and yeast extract based on biomass production, $\beta$-galactosidase production, lactose, and free amino nitrogen residual at $21 \mathrm{~h}$ of cultivation period.

\begin{tabular}{lcccc}
\hline $\begin{array}{l}\text { Skim milk } \\
(\% \mathrm{wt} / \mathrm{vol})^{*}\end{array}$ & $\begin{array}{c}\text { Biomass production } \\
\left(\log _{10} \mathrm{cfu} / \mathrm{mL}\right)\end{array}$ & $\begin{array}{c}\beta \text {-Galactosidase } \\
\text { production } \\
(\mathrm{U} / \mathrm{mL})\end{array}$ & $\begin{array}{c}\text { Lactose } \\
(\mathrm{g} / \mathrm{L})\end{array}$ & $\begin{array}{c}\text { Free amino } \\
\text { nitrogen } \\
(\mathrm{mg} / \mathrm{L})\end{array}$ \\
\hline 0 & $1.03 \pm 0.11^{\mathrm{a} * *}$ & $0.35 \pm 0.21^{\mathrm{a}}$ & $0.00 \pm 0.00^{\mathrm{a}}$ & $141.57 \pm 18.90^{\mathrm{a}}$ \\
4 & $7.19 \pm 0.07^{\mathrm{b}}$ & $6.36 \pm 0.16^{\mathrm{b}}$ & $7.25 \pm 2.02^{\mathrm{b}}$ & $153.80 \pm 15.46^{\mathrm{a}}$ \\
7.17 (optimized & $7.35 \pm 0.06^{\mathrm{b}}$ & $6.34 \pm 0.08^{\mathrm{b}}$ & $15.92 \pm 3.23^{\mathrm{c}}$ & $198.73 \pm 13.67^{\mathrm{a}}$ \\
concentrations) & $7.78 \pm 0.55^{\mathrm{b}}$ & $5.54 \pm 1.02^{\mathrm{b}}$ & $21.39 \pm 3.29^{\mathrm{c}}$ & $251.57 \pm 18.71^{\mathrm{b}}$ \\
10 & $7.52 \pm 0.63^{\mathrm{b}}$ & $5.23 \pm 0.56^{\mathrm{b}}$ & $25.98 \pm 3.19^{\mathrm{c}}$ & $282.27 \pm 11.13^{\mathrm{b}}$ \\
12 & $7.79 \pm 0.45^{\mathrm{b}}$ & $0.05 \pm 0.11^{\mathrm{a}}$ & $0.00 \pm 0.00^{\mathrm{a}}$ & $374.20 \pm 16.22^{\mathrm{c}}$ \\
TPY & & &
\end{tabular}

${ }^{*}$ Cultivation was conducted in different concentrations of skim milk with $1.02 \%$ yeast extract supplementation.

${ }^{* * *}$ Values in the same column with different letters were significantly different $(P<0.05)$.

growth of bifidobacteria [13]. Therefore, yeast extract is included in (4) to (5). Consider

$$
y_{1}=7.14+1.01 x_{1}-6.67 \times 10^{-3} x_{2}-0.93 x_{1}^{2}-0.055 x_{1} x_{2} .
$$

Table 6 shows ANOVA result of quadratic model. Biomass production is significant as indicated by $P$ value $(P<0.001)$. The $R^{2}$ implies the sample variation of $99.93 \%$ for biomass production $\left(y_{1}\right)$ and this indicates that only about $0.07 \%$ of total variation is not explained by the model, indicating good agreement between the experimental and predicted values for biomass production. The lack of fit measures the failure of the model to represent data in the experimental domain at points, which are not included in the regression [24]. The value of lack of fit for regression is insignificant $(P>0.05)$, suggesting that the model fitted well to the data in the experimental region. Moreover, second-order terms were found sufficient and higher order terms were not necessary.

The response surface model shown in Figure 1 indicated that skim milk concentration (\% wt/vol) was the most important factor in the medium. Lactose in milk was able to supply readily utilizable carbon for growth of G4. Increased milk concentration, with small addition of yeast extract as growth enhancer, significantly increased biomass production. Lactose in milk induced $\beta$-galactosidase biosynthesis in Bifidobacterium strain, which break down lactose into glucose and galactose more efficiently during the cultivation process [13]. The response surface obtained is a stationary edge system, whereby the maximum value is a plane platform rather than point form. Thus, there is flexibility in choosing the appropriate optimum points [25].

Based on the optimum point acquired from response surface methodology, the combination of $7.17 \%$ (wt/vol) skim milk, $x_{1}$, and $1.02 \%$ (wt/vol) yeast extract, $x_{2}$, was predicted to produce $7.44 \log _{10} \mathrm{cfu} / \mathrm{mL}$ biomass. This prediction was verified by a validation experiment. A maximum biomass of $7.35 \log _{10} \mathrm{cfu} / \mathrm{mL}$ was obtained from replication experiments. Even though the experimental value was lower than the predicted value, no statistical difference $(P>0.05)$ was observed. In order to observe other growth activities of G4 
TABLE 8: ANOVA analysis for responses $y_{2}$ ( $\beta$-galactosidase: $\left.\mathrm{U} / \mathrm{mL}\right), y_{3}$ (lactose: $\mathrm{g} / \mathrm{L}$ ), and $y_{4}(\mathrm{FAN}: \mathrm{mg} / \mathrm{L}$ ).

\begin{tabular}{|c|c|c|c|c|c|}
\hline Source & Sum squares & DF & Mean square & $F$ value & $P$ value \\
\hline \multicolumn{6}{|l|}{$y_{2}$} \\
\hline Model & 96.50 & 5 & 19.30 & 52.91 & $<0.0001$ \\
\hline Residual & 2.55 & 7 & 0.36 & & \\
\hline Lack of fit & 1.33 & 3 & 0.44 & 1.46 & 0.3521 \\
\hline Pure error & 1.22 & 4 & 0.30 & & \\
\hline \multicolumn{6}{|l|}{$R^{2}=0.9742$} \\
\hline \multicolumn{6}{|l|}{$y_{3}$} \\
\hline Model & 151.33 & 2 & 75.66 & 615.28 & $<0.0001$ \\
\hline Residual & 1.23 & 10 & 0.12 & & \\
\hline Lack of fit & 1.05 & 6 & 0.17 & 3.83 & 0.1075 \\
\hline Pure error & 0.18 & 4 & 0.046 & & \\
\hline \multicolumn{6}{|l|}{$R^{2}=0.9919$} \\
\hline \multicolumn{6}{|l|}{$y_{4}$} \\
\hline Model & 14609.65 & 5 & 2921.93 & 123.58 & 0.0001 \\
\hline Residual & 165.51 & 7 & 23.64 & & \\
\hline Lack of fit & 126.17 & 3 & 42.06 & 4.28 & 0.0971 \\
\hline Pure error & 39.34 & 4 & 9.84 & & \\
\hline$R^{2}=0.9888$ & & & & & \\
\hline
\end{tabular}

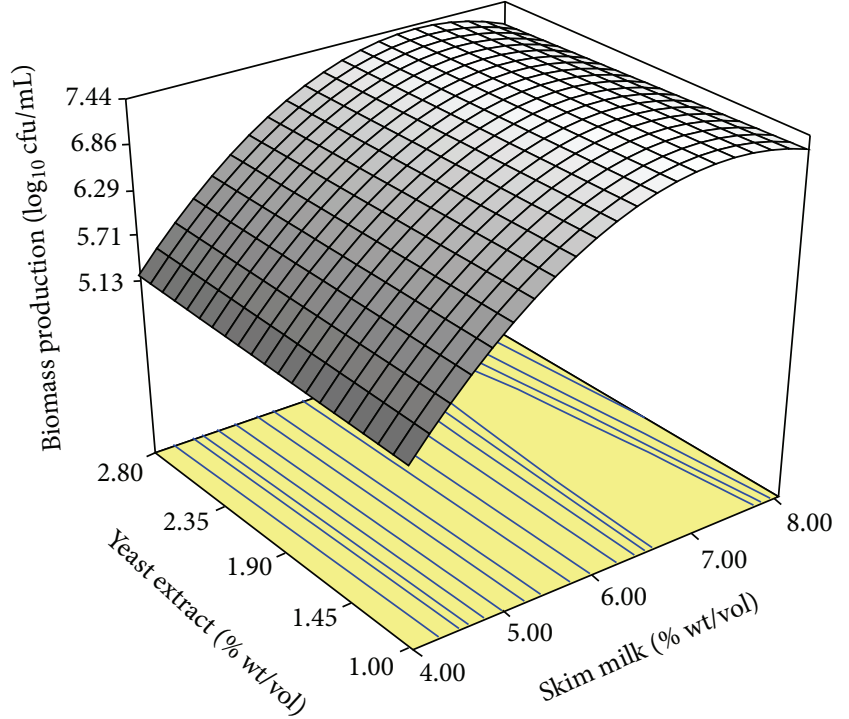

FIGURE 1: Response surface methodology for biomass production $\left(\log _{10} \mathrm{cfu} / \mathrm{mL}\right)$ from the adjusted quadratic mathematical model.

in optimized medium, analysis of $\beta$-galactosidase production as well as determination of lactose and free amino nitrogen residual in the culture at $21 \mathrm{~h}$ of cultivation was performed. As shown in Table 7, the optimized medium (7.17\% (wt/vol) skim milk and $1.02 \%$ (wt/vol) yeast extract) was able to support G4 growth up to $7 \log _{10} \mathrm{cfu} / \mathrm{mL}$ with substantially high $\beta$ galactosidase production at $21 \mathrm{~h}$ of cultivation. However, high amount of lactose and free amino nitrogen residual was still observed at the end of cultivation. To avoid wastage of nutrients remaining in the medium, further optimization step was carried out by considering residual nutrients remaining in the culture at the end of cultivation. This step was conducted and presented in the following section.

3.2.2. $\beta$-Galactosidase Production $\left(y_{2}\right)$, Lactose $\left(y_{3}\right)$, and Free Amino Nitrogen $\left(y_{4}\right)$ Presence as Responses. Further optimization of G4 medium cultivation was carried out by including $\beta$-galactosidase production, lactose, and free amino nitrogen balance at $21 \mathrm{~h}$ of cultivation as responses. The responses $\left(y_{2}, y_{3}\right.$, and $\left.y_{4}\right)$ were fitted with the second-order polynomial equations

$$
\begin{gathered}
y_{2}=8.87+2.19 x_{1}+0.57 x_{2}-3.97 x_{1}^{2} \\
-0.88 x_{2}^{2}-0.94 x_{1} x_{2}, \\
y_{3}=9.64+5.02 x_{1}-0.15 x_{2}, \\
y_{4}=235.68+45.95 x_{1}+121.79 x_{2}+12.64 x_{1}^{2} \\
+7.01 x_{2}^{2}+4.05 x_{1} x_{2} .
\end{gathered}
$$

The statistical significance of the model was evaluated by the $P$ value of the analysis of variance (ANOVA). ANOVA statistics for the three responses, $y_{2}$ ( $\beta$-galactosidase), $y_{3}$ (lactose residual), and $y_{4}$ (free amino nitrogen residual), at $21 \mathrm{~h}$ of the cultivation period are shown in Table 8. Quadratic models for $y_{2}$ and $y_{4}$ as well as linear model for $y_{3}$ are highly significant, as shown by low probability value $(P<0.001)$. The models fitted well to the experimental design as lack of fit for all three responses is insignificant $(P>0.05)$. Moreover, the coefficient of determinations $\left(R^{2}\right)$ is close to $1\left(y_{2}: 0.97\right.$, $y_{3}: 0.99$, and $\left.y_{4}: 0.98\right)$, indicating high degree of correlation between observed and predicted values. 


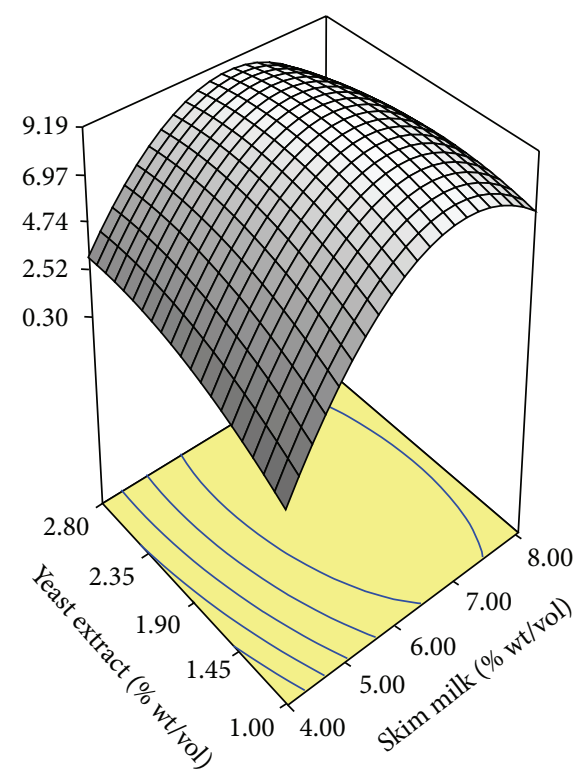

(a)

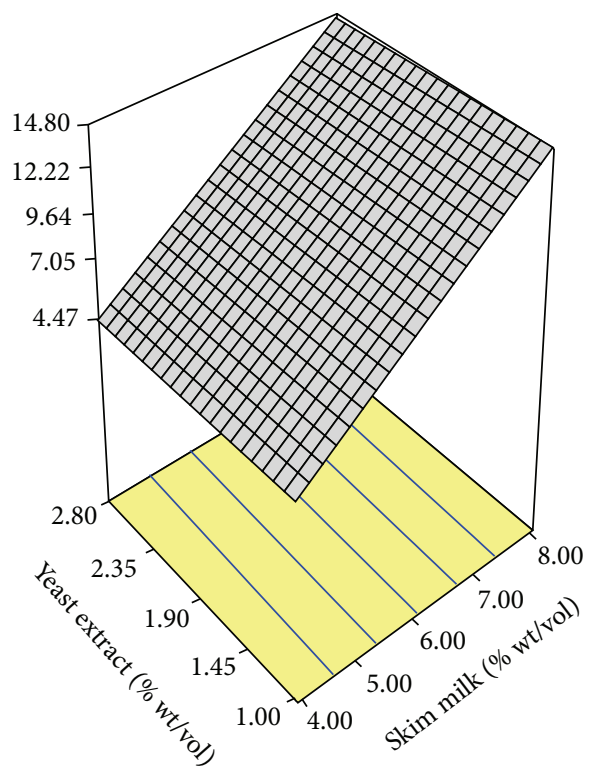

(b)

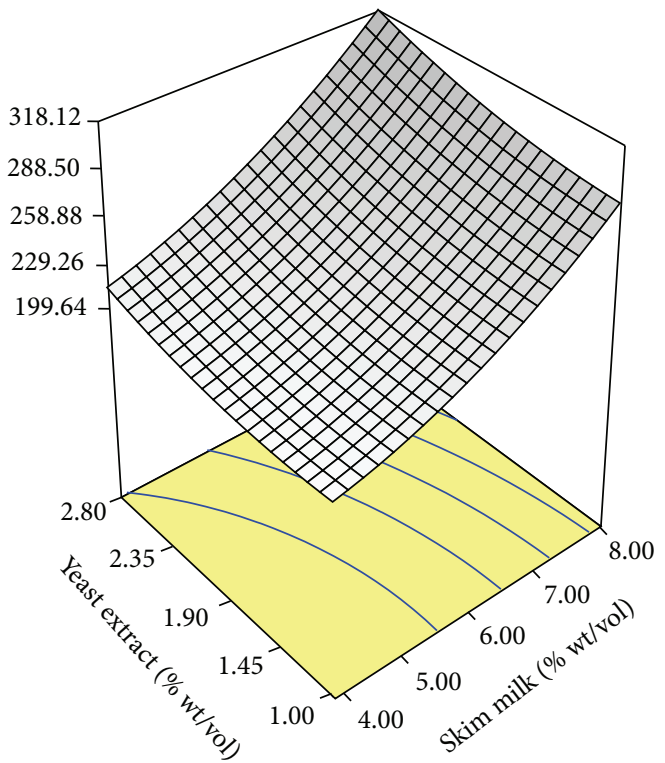

(c)

FIGURE 2: Response surface plot of the effect of skim milk and yeast extract concentration (\% wt/vol) for the responses of (a) $\beta$-galactosidase production $(\mathrm{U} / \mathrm{mL}),(\mathrm{b})$ lactose residual $(\mathrm{g} / \mathrm{L})$, and (c) free amino nitrogen residual $(\mathrm{mg} / \mathrm{L})$ at $21 \mathrm{~h}$ of cultivation period.

The response surface plot of $\beta$-galactosidase production $\left(y_{2}\right)$ is shown in Figure 2(a). High production of $\beta$ galactosidase was observed at the middle range of skim milk (6.00 to $7.00 \%$ (wt/vol)). On the other hand, reduced production of $\beta$-galactosidase was detected at high and low point of skim milk concentration. The use of high skim milk concentration $(8.00 \%$ (wt/vol)) might contribute to the presence of high lactose concentration and this could suppress $\beta$-galactosidase production. Medium containing high lactose concentration ( $>5 \%$ [wt/vo]), may attributed to increase in the concentration of internally glucose. It has been reported that the increased of internal glucose would suppressed the biosynthesis of $\beta$-galactosidase by tested organisms [26]. The presence of low lactose concentration in the medium using low skim milk concentration $(4.00 \%$ (wt/vol)) may not induce $\beta$-galactosidase production.

A linear response surface plot of lactose residual $\left(y_{3}\right)$ is shown in Figure 2(b). At high skim milk concentration $(8.00 \%(\mathrm{wt} / \mathrm{vol}))$ residual lactose concentration at $21 \mathrm{~h}$ of cultivation reached a maximum value with minor changes in yeast extract ( $1 \%$ to $2.8 \%(\mathrm{wt} / \mathrm{vol}))$. In contrast, very low residual glucose concentration was detected at low skim milk concentration $(4.00 \%(\mathrm{wt} / \mathrm{vol}))$. This response indicated that skim milk concentration ( $4 \%$ to $8 \%(\mathrm{wt} / \mathrm{vol})$ ) was closely 
associated with residual lactose concentration. On the other hand, yeast extract ranging from $1 \%$ to $2.8 \%$ (wt/vol)) had less significant effect on the response. However, the presence of yeast extract was required to support $\beta$-galactosidase production (Figure 2(a)). Minimum residual lactose concentration at $21 \mathrm{~h}$ of cultivation was considered in this optimization method to avoid wastage of carbon source. From this point of view, low skim milk concentration is preferred to be used as cultivation medium for G4.

Figure 2(c) shows response surface plot representing free amino nitrogen residual concentration in the culture at $21 \mathrm{~h}$ of cultivation. The presence of nitrogen in medium was attributed to yeast extract and skim milk as well as dead cells and was believed to sustain bacterial growth. Similar to lactose, minimum residual concentration of nitrogen remaining in the culture after $21 \mathrm{~h}$ was considered in the optimization to avoid wastage of nitrogen source. The response surface generated based on the second-order coefficient shows that skim milk and yeast extract presented a quadratic effect (Figure 2(c)). The use of skim milk at high concentration with increasing yeast extract concentration (ranging from $1 \%$ to $2.8 \%(\mathrm{wt} / \mathrm{vol}))$ significantly influenced the residual concentration of free amino nitrogen in the culture. On the other hand, reduced residual concentration of free amino nitrogen in the culture was observed at low skim milk concentration $(4.00 \%$ (wt/vol)) with decreasing yeast extract concentration (ranging from $2.8 \%$ to $1 \%$ (wt/vol)). This result indicated that interactions between skim milk and yeast extract might have a stronger influence on residual concentration of free amino nitrogen remaining in the culture. Consequently, the use of low skim milk and yeast extract concentration significantly improved the nitrogen uptake efficiency with low residual concentration remaining in the culture at the end of cultivation.

3.3. Validation of Optimized Medium. The optimum concentrations for skim milk and yeast extract were $5.89 \%$ (wt/vol) and $2.31 \%$ (wt/vol), respectively. The responses criteria for the optimization process were maximum for biomass and $\beta$ galactosidase production. On the other hand, the minimum values were set for residual concentration of lactose and free amino nitrogen. An experiment was performed under the predicted optimal conditions in order to validate the optimized medium. The experimental values fitted well to the predicted results with no significant difference $(P>$ $0.05)$. Therefore, this result was encountered in the process of validation of response surface methodology optimization.

\section{Conclusion}

Results from this study have demonstrated that the optimization of milk-based medium using response surface methodology (RSM) greatly improved G4 cultivation performance, in terms of final cell concentration and $\beta$-galactosidase as well as residual concentration of lactose and amino nitrogen remaining in the culture. The quadratic model (biomass, $\beta$ galactosidase production, and free amino nitrogen residual) and linear model (lactose residual) were found sufficient for the optimization of medium for G4. The optimal medium that consists of 5.89\% (wt/vol) skim milk and $2.31 \%(\mathrm{wt} / \mathrm{vol}$ ) yeast extract gave the final biomass count of $10^{7} \mathrm{cfu} / \mathrm{mL}, \beta$ galactosidase activity of $8.74 \mathrm{U} / \mathrm{mL}$, residual lactose concentration of $9.15 \mathrm{~g} / \mathrm{L}$, and residual free amino nitrogen concentration of $226.07 \mathrm{mg} / \mathrm{mL}$. In addition, the use of this optimal medium gave comparable biomass count and $\beta$-galactosidase activity as those obtained in cultivation using high skim milk concentrations ( $10 \%$ to $13 \%$ (wt/vol)). However, residual lactose and free amino nitrogen concentration remaining in the culture at the end of cultivation were reduced by about two times lower as compared to those observed in cultivation using high skim milk concentration.

\section{Conflict of Interests}

The authors declare no conflict of interests.

\section{Acknowledgments}

This study was funded by the Ministry of Higher Education, Malaysia, under Project no. 600-RMI/FRGS 5/13 15/2013. The first author is also grateful to Universiti Teknologi MARA (UiTM), Malaysia, and Universiti Putra Malaysia (UPM) for the support throughout the conduct of this study.

\section{References}

[1] FAO/WHO, "Health and nutritional properties of probiotics in food including powder milk with live lactic: report of a joint $\mathrm{FAO} / \mathrm{WHO}$ expert consultation on acid bacteria expert consultation on evaluation of health and nutritional properties of probitics in food including powder milk with live lactic acid bacteria," Tech. Rep., 2001.

[2] Y. Ohashi and K. Ushida, "Health-beneficial effects of probiotics: its mode of action," Animal Science Journal, vol. 80, no. 4, pp. 361-371, 2009.

[3] T. Mitsouka, "Taxonomy and ecology of bifidobacteria," Bifdobacteria Microflora, no. 3, pp. 11-28, 1984.

[4] V. Scardovi, “Genus Bifidobacterium," in Bergey's Manual of Systemic Bacteriology, N. N. S. Mair, Ed., pp. 1418-1434, William and Wilkins, New York, NY, USA, 1986.

[5] M. Shuhaimi, A. M. Ali, N. M. Saleh, and A. M. Yazid, "Differentiation of Bifidobacterium isolates from faeces of infant by RAPD," Bioscience Microflora, vol. 20, pp. 89-94, 2001.

[6] M. Shuhaimi, A. M. Ali, N. M. Saleh, and A. M. Yazid, "Utilisation of Enterobacterial Repetitive Intergenic Consensus (ERIC) sequence-based PCR to fingerprint the genomes of Bifidobacterium isolates and other probiotic bacteria," Biotechnology Letters, vol. 23, no. 9, pp. 731-736, 2001.

[7] M. Shuhaimi, A. M. Ali, M. S. Norihan, and A. M. Yazid, "Classification of Bifidoacteriumisolates from infant faeces using PCR-based and 16S rdnapartial sequence analysis methods," Bioscience Microflora, vol. 21, pp. 155-161, 2002.

[8] S. Wong, Y. K. Wendy, B. M. Kabeir, M. Shuhaimi, M. Rosfarizan, and A. M. Yazid, "Survival of Bifidobacterium pseudocatenulatum strain isolated from breast-fed infants to simulated gastric $\mathrm{pH}$ environment," Malaysian Applied Biology, vol. 35, pp. 57-62, 2006. 
[9] L. R. Rodrigues, J. A. Teixeira, and R. Oliveira, "Low-cost fermentative medium for biosurfactant production by probiotic bacteria," Biochemical Engineering Journal, vol. 32, no. 3, pp. 135-142, 2006.

[10] J. Mark, "Successful probiotic bacteria," in Handbook of Functional Dairy Products, C. Shortt and J. O'Brien, Eds., pp. 36-61, CRC Press, Boca Raton, Fla, USA, 2004.

[11] V. M. Marshall and A. Y. Tamime, "Starter cultures employed in the manufacture of biofermented milks," International Journal of Dairy Technology, vol. 50, no. 1, pp. 35-41, 1997.

[12] H. M. Østlie, M. H. Helland, and J. A. Narvhus, "Growth and metabolism of selected strains of probiotic bacteria in milk," International Journal of Food Microbiology, vol. 87, no. 1-2, pp. 17-27, 2003.

[13] C. A. Hsu, R. C. Yu, and C. C. Chou, "Production of $\beta$ galactosidase by Bifidobacteria as influenced by various culture conditions," International Journal of Food Microbiology, vol. 104, no. 2, pp. 197-206, 2005.

[14] L. Avonts, E. V. Uytven, and L. D. Vuyst, "Cell growth and bacteriocin production of probiotic Lactobacillus strains in different media," International Dairy Journal, vol. 14, no. 11, pp. 947-955, 2004.

[15] A. Shihata and N. P. Shah, "Proteolytic profiles of yogurt and probiotic bacteria," International Dairy Journal, vol. 10, no. 5-6, pp. 401-408, 2000.

[16] R. I. Dave and N. P. Shah, "Evaluation of media for selective enumeration of Streptococcus thermophilus, Lactobacillus delbrueckii ssp. bulgaricus, Lactobacillus acidophilus, and Bifidobacteria," Journal of Dairy Science, vol. 79, no. 9, pp. 1529$1536,1996$.

[17] W. Stephanie, B. M. Kabier, M. Shuhaimi, M. Rosfarizan, and A. M. Yazid, "Growth optimization of a probiotic candidate, Bifidobacterium pseudocatenulatum G4, in milk medium using response surface methodology," Biotechnology and Bioprocess Engineering, vol. 12, no. 2, pp. 106-113, 2007.

[18] M.-J. Chen, K.-N. Chen, and C.-W. Lin, "Optimization on response surface models for the optimal manufacturing conditions of dairy tofu," Journal of Food Engineering, vol. 68, no. 4, pp. 471-480, 2005.

[19] F. Karacan, U. Ozden, and S. Karacan, "Optimization of manufacturing conditions for activated carbon from Turkish lignite by chemical activation using response surface methodology," Applied Thermal Engineering, vol. 27, no. 7, pp. 1212-1218, 2007.

[20] J.-W. Hou, R.-C. Yu, and C.-C. Chou, "Changes in some components of soymilk during fermentation with bifidobacteria," Food Research International, vol. 33, no. 5, pp. 393-397, 2000.

[21] M. N. Hwang and G. M. Ederer, "Rapid hippurate hydrolysis method for presumptive identification of group B streptococci," Journal of Clinical Microbiology, vol. 1, no. 1, pp. 114-115, 1975.

[22] Z. Nagy, T. Kiss, A. Szentirmai, and S. Biro, "Carbon source regulation of $\beta$-galactosidase biosynthesis in Penicillium chrysogenum," Journal of Basic Microbiology, vol. 41, pp. 351-362, 2001.

[23] B. K. Körbahti, N. Aktaş, and A. Tanyolaç, "Optimization of electrochemical treatment of industrial paint wastewater with response surface methodology," Journal of Hazardous Materials, vol. 148, no. 1-2, pp. 83-90, 2007.

[24] H. Gao and W.-Y. Gu, "Optimization of polysaccharide and ergosterol production from Agaricus brasiliensis by fermentation process," Biochemical Engineering Journal, vol. 33, no. 3, pp. 202-210, 2007.
[25] R. H. Myers and D. C. Montgomery, Response Surface Methodology: Process and Product Optimization Using Designed Experiments, John Wiley \& Sons, New York, NY, USA, 2nd edition, 2002.

[26] E. Demirhan, D. K. Apar, and B. Özbek, "Product inhibition of whey lactose hydrolysis," Chemical Engineering Communications, vol. 195, no. 3, pp. 293-304, 2008. 

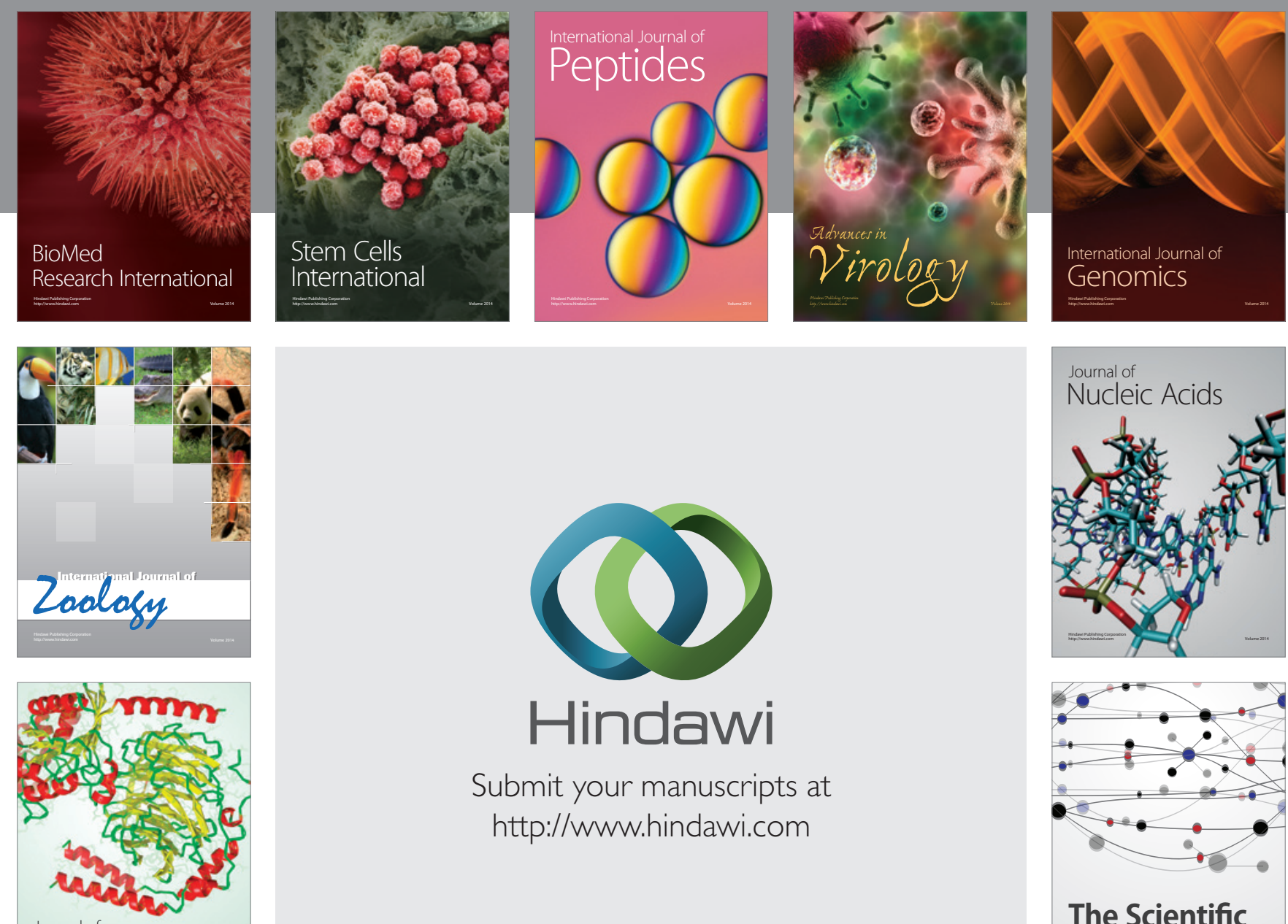

Submit your manuscripts at

http://www.hindawi.com

Journal of
Signal Transduction
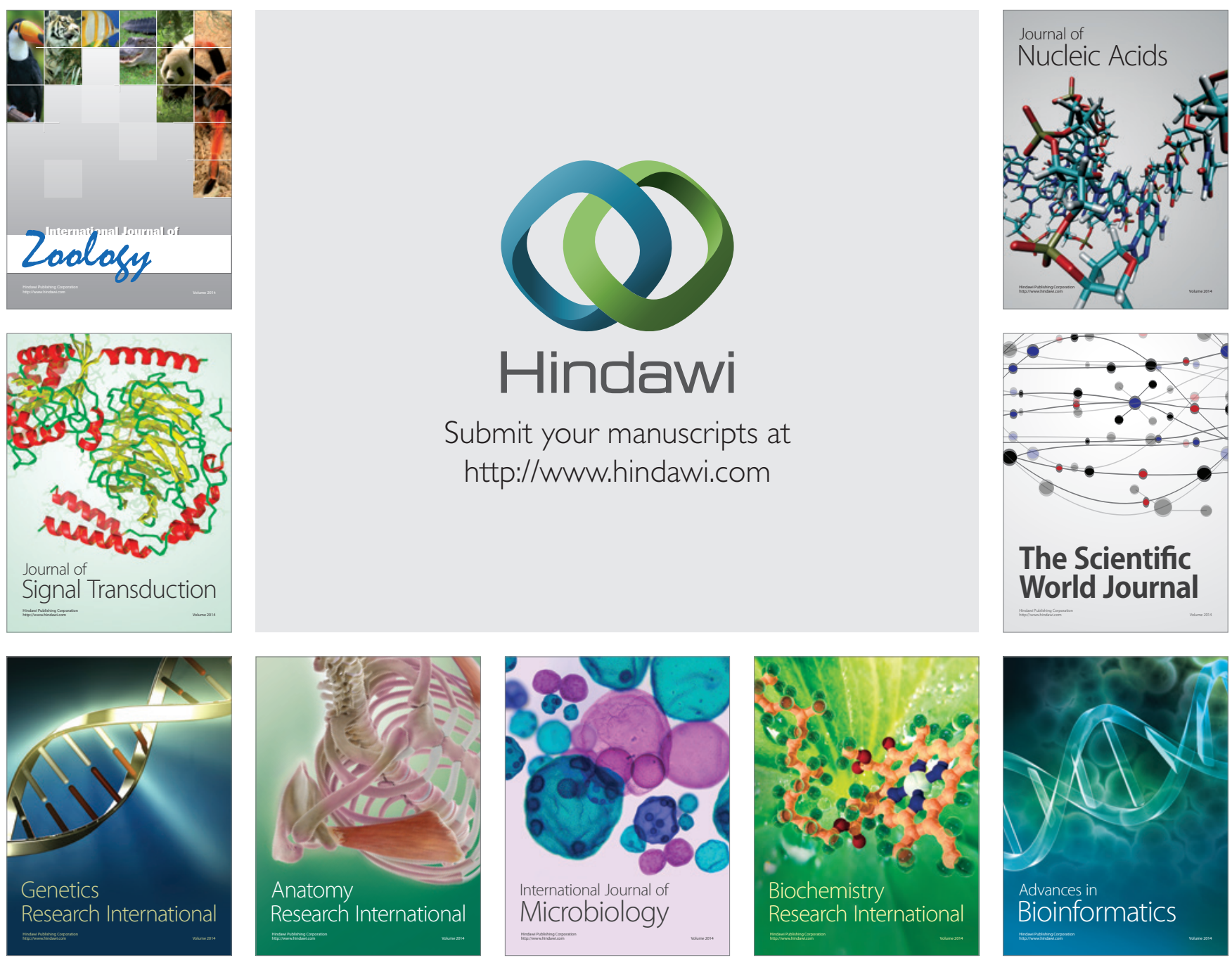

The Scientific World Journal
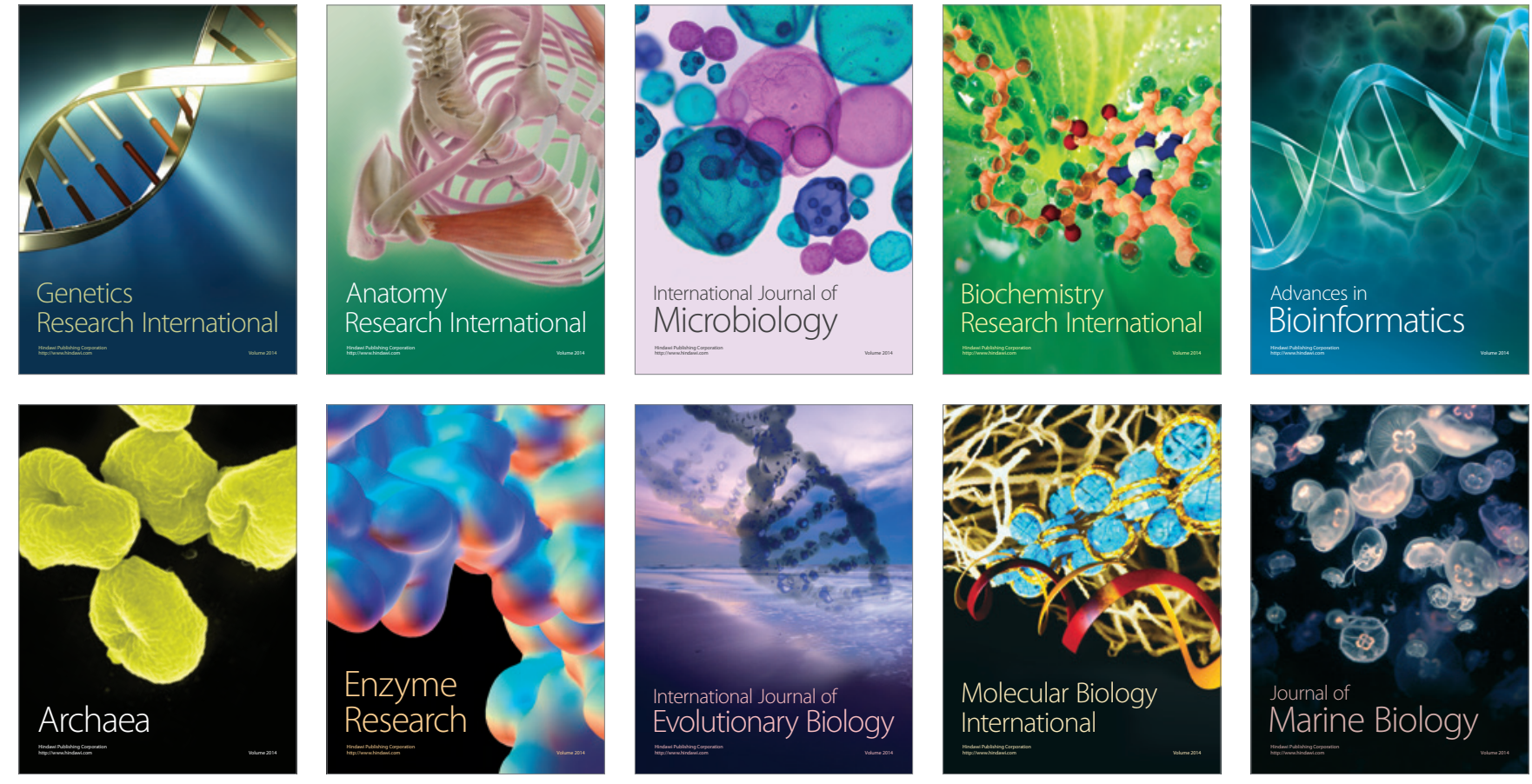